\title{
PORTARSE MAL: EL COMPORTAMIENTO IRRACIONAL EN LA VIDA ECONÓMICA
}

\author{
EDITORIAL: PAIDÓS
}

FECHA DE PUBLICACIÓN: 2017

AUTOR: RICHARD H. THALER

NÚMERO DE PÁGINAS: 528

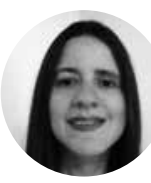

\author{
VIVIANA H. PEÑA \\ - Profesora de management \\ Facultad de Negocios, UPC
}

Richard H. Thaler, un economista que durante 40 años ha pasado largas horas en las prestigiosas universidades de Rochester, Cornell, MIT y, desde 1995 en Chicago, donde predomina el pensamiento económico clásico, más prevaleciente de la era contemporánea, ha decidido reconocer que incluso en el seno de una institución como Booth, la Escuela de Negocios de la Universidad de Chicago, hay cabida para pensar diferente y, que en efecto, lo ha venido haciendo dentro de la misma Escuela.

El título de su reciente libro, "Portase mal", es solo un mea culpa para la exportación y acaso para atraer las miradas de los lectores incautos, quizá por el hecho de haberse dedicado al estudio de lo que en realidad hace la gente, en vez de lo que debería hacer la gente para tomar decisiones; por lo que el titulo bien podría ser "Comportarse". Su libro es el resultado de muchos años de trabajo y de observaciones; y cabría preguntarse si en realidad es la historia de la "economía conductual" desde el seno de quienes la crearon y que el autor talentosamente sabe narrar alternando con abundantes anécdotas personales de sus muchas vivencias y reflexiones. Un deleite para curiosos de las biografías, la historia, la economía y las ciencias de la conducta.

Thaler, actualmente, es considerado el padre de la economía conductual por sus investigaciones en el comportamiento de los agentes económicos, así como de la psicología de la toma de decisiones, lo que constituye el límite entre la economía y la psicología. Sin embargo, como él mismo lo señala, John Maynard Keynes lo habría precedido cuando afirmaba que las emociones o los "espíritus animales", como él los llamó en su momento, desempeñan un papel trascendental en las decisiones de inversión.

Son varias las menciones a Kahneman y Tversky, a quienes conoció personalmente en los años '70 y de quienes se nutrió en sus inicios; y a Loewenstein, Shiller y Camerer en los años '80. Llama la atención que no haya mención a Maurice Allaise, quien habría diseñado los primeros experimentos de la economía conductual, como campo de investigación. Se omiten los autores europeos, principalmente británicos, por lo que podría considerarse un texto estadounidense-israelí.

La temática del libro es sustanciosa. Entre los conceptos centrales que el libro aborda está la maximización de la utilidad esperada como ideal normativo para la toma de decisiones, lo que es sin duda discutible, en tanto que la evidencia apunta que en algunos casos podría dejarse esta premisa en aras de un ideal o valor más alto. Sin embargo, la mayor parte del volumen está dedicado a la investigación a la que Thaler ha estado dedicado por varias décadas. Las ideas, como las de que la gente valora más un bien cuando lo posee que antes de tenerlo; o la de la contabilidad mental, por la cual las personas abonarían el pago mínimo de su tarjeta de crédito aun teniendo el dinero para pagar la deuda total, con lo que terminarían pagando más en intereses que lo que reciben por sus ahorros, conforman algunas de las interrogantes centrales de su larga investigación. Aborda también el sesgo del presente, por el que le daríamos más importancia a la situación del presente que a otros hechos; y, la utilidad de transacción, el disfrute que se obtiene de un buen negocio vs. el dolor que se sufre al ser timado, lo que se contradice con la teoría establecida de que sólo la ganancia importa.

Thaler muestra algunos vestigios de ambivalencia pero su análisis de las posibles causas de los hallazgos de la economía conductual muestra que la gente frecuentemente se comporta de manera poco racional aunque en algunas circunstancias se ajusta a los cánones convencionales. Sin duda, "Portase mal" es un buen lugar para comenzar si de economía conductual se trata. 